\title{
IE'09 best paper award by JAISE
}

During the 6th edition of the International Conference on Intelligent Environments (IE'10) held in Kuala Lumpur (Malaysia) last July, JAISE provided a prize to the best paper of the conference. The prize for the best paper consists of one year free subscription to JAISE and other products accessible through MetaPress kindly provided by IOS Press, the publisher of JAISE.

The chairs of the conference directly based upon the votes of the attendees to the conference awarded the prize to the paper:

"A Coordination Framework for Pervasive Applications in Multi-User Environments" by Verena Majuntke, Gregor Schiele, and Kai Spohrer from Universität Mannheim (Germany) and Marcus Handte and Christian Becker from Universität Bonn (Germany).

The photo in Fig. 1 shows Juan Carlos Augusto (coeditor in chief of JAISE) congratulating the first author on behalf of JAISE.
JAISE and IOS Press plan to extend this practice to other major events in related fields as a way to stimulate high quality research around the world in the area of Ambient Intelligence and Smart Environments.

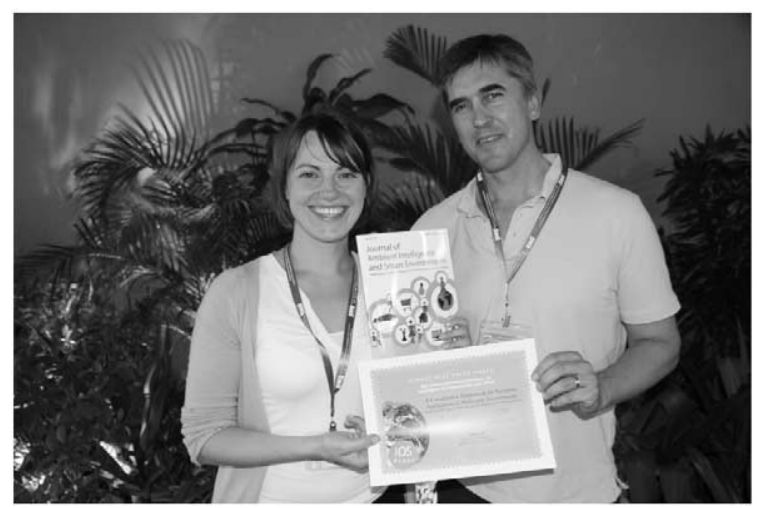

Fig. 1. JAISE congratulates the winner 